\title{
Adipose-derived stem cells prevent the onset of bisphosphonate-related osteonecrosis of the jaw through transforming growth factor $\beta$-1-mediated gingival wound healing
}

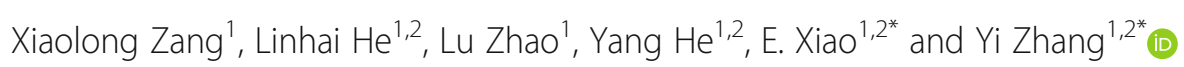

\begin{abstract}
Background: Due to its complex pathogenesis and low clinical cure rate, bisphosphonate-related osteonecrosis of the jaw (BRONJ) poses a substantial challenge for oral and maxillofacial surgeons. Therefore, the treatment of BRONJ should focus on prevention. In clinical studies, primary wound closure can significantly reduce the incidence of BRONJ. Whether local stem cell transplantation can promote primary gingival healing in patients with a medication history and prevent BRONJ has not been reported.
\end{abstract}

Methods: In this study, animals were divided into a healthy group (non-drug treatment), a BP group, a hydroxyapatite (HA) group, and an adipose-derived stem cell (ADSC) group. All groups except the healthy group were treated with BPs and immunosuppressive drugs once per week for 8 weeks, simulating clinical use for the treatment of cancer patients with bone metastasis, to induce BRONJ-like animals. After the sixth drug treatment, the bilateral premolars were extracted in all groups. In contrast to the healthy and BP groups, the extraction sockets in the HA and ADSC groups were filled with HA or HA + ADSCs simultaneously post extraction to observe the preventive effect of ADSCs on the occurrence of BRONJ. At 2 and 8 weeks post extraction, animals from all groups were sacrificed.

Results: At 8 weeks post transplantation, ADSCs prevented the occurrence of BRONJ, mainly through accelerating healing of the gingival epithelium at 2 weeks post extraction. We also found that ADSCs could upregulate the expression of transforming growth factor $\beta 1$ (TGF- $\beta 1$ ) and fibronectin in tissue from animals with a medication history by accelerating gingival healing of the extraction socket. A rescue assay further demonstrated that TGF- $\beta 1$ and fibronectin expression decreased in TGF- $\beta 1$-deficient ADSC-treated animals, which partially abolished the preventive effect of ADSCs on the onset of BRONJ.

Conclusion: ADSCs prevent the onset of BRONJ, mainly by upregulating the expression of TGF- $\beta 1$ and fibronectin to promote primary gingival healing, ultimately leading to bone regeneration in the tooth extraction socket. Our new findings provide a novel stem cell treatment for the prevention of BRONJ.

Keywords: Bisphosphonate-related osteonecrosis of the jaw, Wound healing, Zoledronic acid, Fibroblast, Fibronectin, Adipose-derived mesenchymal stem cells

\footnotetext{
* Correspondence: xiaoe1986@vip.163.com; zhangyi2000@263.net

'Department of Oral and Maxillofacial Surgery, Peking University School and Hospital of Stomatology, 22 Zhongguancun Nandajie, Haidian District, Beijing 100081, People's Republic of China

Full list of author information is available at the end of the article
}

(c) The Author(s). 2019 Open Access This article is distributed under the terms of the Creative Commons Attribution 4.0 International License (http://creativecommons.org/licenses/by/4.0/), which permits unrestricted use, distribution, and reproduction in any medium, provided you give appropriate credit to the original author(s) and the source, provide a link to the Creative Commons license, and indicate if changes were made. The Creative Commons Public Domain Dedication waiver (http://creativecommons.org/publicdomain/zero/1.0/) applies to the data made available in this article, unless otherwise stated. 


\section{Background}

Bisphosphonate-related osteonecrosis of the jaw (BRONJ) is defined as a type of disease in which jaw bone is exposed in the maxillofacial region and persists for no less than 8 weeks in patients who are undergoing bisphosphonate treatment and have no oral radiation history [1]. BRONJ is a type of medication-related osteonecrosis of the jaw (MRONJ) and has been correlated with high doses of bisphosphonates (BPs) [2]. In addition, BRONJ was frequently observed in bone metastatic tumor patients who were treated in conjunction with immunosuppressive agents, and its incidence increased to $18 \%$ [3]. Dexamethasone, as the most common immunosuppressive drug, was used to treat multiple myeloma and bone metastasis and was also required for the development of a BRONJ-like disease model $[4,5]$. The main clinical manifestations are impaired gingival wound healing and bone exposure, with necrotic bone formation accompanied by pain or sinus formation [1]. Among the risk factors, jaw trauma, especially tooth extraction and apical surgery, is a high-risk factor for BRONJ [6]. To date, this disease still lacks effective treatments, and only $59 \%$ of cases can be partially or completely healed [7]. In view of the low clinical cure rate, the treatment of BRONJ should focus on prevention.

Recent studies have indicated that primary closure after tooth extraction in BP-treated patients can effectively reduce the occurrence of BRONJ [8-10]. Notably, no MRONJ was observed when the tooth extraction wound was completely closed with a relaxation incision and/or sharp bone edges were removed, whereas an open wound increased the incidence to $56.1 \%$ [11]. Therefore, a soft tissue covering would reduce the occurrence of BRONJ.

Adipose-derived stem cells (ADSCs) are harvested from subcutaneous fat, are a rich source of cellular factors and promote angiogenesis, which makes them suitable for soft tissue repair [12-15]. ADSCs promote wound healing and antioxidation by paracrine cytokine activation [16, 17]. Stem cell-based treatment strategies are currently an effective method for the treatment of BRONJ. Notably, BRONJlike lesions in mice and minipig models were successfully induced by BPs combined with dexamethasone and cured by systemic infusion of mesenchymal stem cells (MSCs) [5, 18]. Nevertheless, systemic infusion of MSCs may induce disseminated intravascular thrombosis and prolonged prothrombin time [19]. Most importantly, in cancer patients, systemic infusion of MSCs increased the risk of cancer metastasis and recurrence [20,21]. To avoid the side effects mentioned above, in this study, we attempted to elucidate whether local application of ADSCs can also prevent the occurrence of BRONJ.

Overall, the present study evaluated the effect of local ADSC transplantation on tooth extraction in BP-treated animals to prevent the occurrence of BRONJ. We hypothesized that local ADSC transplantation would induce soft tissue repair and prevent the occurrence of BRONJ after tooth extraction.

\section{Methods \\ Animals}

New England rabbits $(n=36)$ weighing $2.0 \mathrm{~kg}$ were used in this study. The animals were housed in a conventional room with a regular dark-light cycle (12 h) at room temperature $\left(20-25^{\circ} \mathrm{C}\right)$. Experimental procedures involving animals followed institutionally approved protocols for animal research at Peking University (LA2018017).

\section{Reagents}

Zoledronic acid was purchased from Sigma (SML0223, St. Louis, MO, USA); dexamethasone was purchased from Sinopharm Group (Shanghai Chemical Reagent Co. Ltd., China); the human TGF- $\beta 1$ ELISA kit (DB$100 \mathrm{~B})$ and anti-TGF- $\beta 1$ (MAB-240) primary antibody were purchased from R\&D Systems (R\&D Systems, Inc., Minneapolis, MN, USA); and the anti-fibronectin primary antibody was purchased from Santa Cruz (sc59826, Santa Cruz Biotech, Santa Cruz, CA, USA).

\section{Induction of a BRONJ-like rabbit model and experimental design}

Rabbits were maintained in a conventional room for 1 week to adapt to the environment. The BP, HA, and ADSC groups then received zoledronic acid $(800 \mu \mathrm{g} / \mathrm{kg}, \mathrm{sml}-0223$, Sigma, USA) and dexamethasone (Dex, $10 \mathrm{mg} / \mathrm{kg}$, Sinopharm Group, China) intravenously (I.V.) once per week for 8 weeks. The bilateral premolars were extracted under deep anesthesia by I.V. injection of pentobarbital $(20 \mathrm{mg} /$ kg, P3761, Sigma, USA) and xylazine (50 $\mu \mathrm{l} / \mathrm{kg}$, Jilin Huamu Animal Health Product Co., Ltd., China) after the sixth dose. For the ADSC group, ADSCs (passage 3-5) incubated on coral hydroxyapatite (HA) were immediately filled into the extraction sockets of animals with a medication history (ADSC group). Non-medication-treated animals and nonfilled animals (healthy group), medicationtreated and nonfilled animals (BP group), and medicationtreated and non-ADSC hydroxyapatite-filled animals (HA group) were used as controls. Then, at 2 and 8 weeks post extraction, the tooth extraction socket and the adjacent first molar were harvested at each indicated time. The unhealed area, necrotic bone, and new bone formation were measured based on clinical appearance and histology. All parameters mentioned above were quantified by Image software (Version $1.51 \mathrm{~s}$, US National Institutes of Health, Bethesda, Maryland).

\section{Formation of the ADSC-hydroxyapatite complex}

The complex of ADSCs and hydroxyapatite was made based on the previously described method [22]. In brief, $5 \times 10^{6}$ ADSCs in $300 \mu \mathrm{l}$ of serum-free $\alpha$-MEM medium 
per $40 \mathrm{mg}$ of spheroidal hydroxyapatite/tricalcium phosphate (HA, Beijing YHJ Science and Trade Co. Ltd.) were used and preincubated at $37{ }^{\circ} \mathrm{C}$ for $30 \mathrm{~min}$ and then kept on ice before filling the socket.

\section{DiR fluorescence labeling of ADSCs}

The commercially available lipophilic tracer 1,1-dioctadecyl-3,3,3,3-tetramethylindotricarbocyanine iodide (DiR; Molecular Probes Inc.) was used to label live ADSCs. In brief, $1 \times 10^{6}$ ADSCs were stained with $1 \mathrm{ml}(2.5 \mu \mathrm{g} / \mathrm{ml})$ of DiRlabeling solution for $30 \mathrm{~min}$ at $37{ }^{\circ} \mathrm{C}$, and the solution was then discarded after centrifugation (1500 rpm, $15 \mathrm{~min}$ ) and resuspended in prewarmed $\left(37^{\circ} \mathrm{C}\right)$ phosphate-buffered saline (PBS). An extra centrifuge step was needed before incubation on HA.

\section{TGF- $\beta 1$ ELISA}

The concentrations of TGF- $\beta 1$ in human gingival fibroblasts (HGFs) and ADSCs were measured with culture supernatant in serum-free medium with a TGF- $\beta 1$ ELISA kit (R\&D, USA) following the manufacturer's instructions.

\section{Isolation and culture of ADSCs and HGFs}

ADSCs were harvested from healthy donors. HGFs were harvested from healthy donors and BRONJ patients without bone metastases. All procedures were approved by the Ethics Committee of Peking University (IRB00001052-11002). The specific process is described in the Additional file 1: Supplemental methods.

\section{Flow cytometry}

The ADSCs were washed 3 times with PBS and harvested by digestion and centrifugation. The cells were then incubated with the following labeled antibodies: CD90-FITC, CD44-PE, CD73-APC, CD105-CY5.5, and negative cocktail-PE. Control-conjugated immunoglobulin G (IgG) was used as the isotype control. All antibodies were purchased from BD Biosciences (No.562245). Flow cytometry was performed with an Accuri C6 flow cytometer (BD Biosciences).

\section{Multi-differentiation assays}

For osteogenic differentiation, third-passage ADSCs were cultured in osteogenic medium supplemented with $10 \mathrm{~nm}$ dexamethasone, $0.1 \mathrm{~mm}$ L-ascorbic acid phosphate, and 10 $\mathrm{mm} \beta$-glycerophosphate (Sigma-Aldrich). The osteogenic medium was changed every 3 days. After 7 days, messenger RNA (mRNA) was isolated for osteogenic genes analysis. After 21 days, calcium nodes were stained with 2\% Alizarin red (Sigma-Aldrich).

For adipogenic differentiation, third-passage BMSCs were cultured in adipogenic culture medium supplemented with $0.5 \mu \mathrm{m}$ hydrocortisone, $0.5 \mathrm{~mm}$ 3-isobutyl-methylxanthine, $10 \mu \mathrm{g} / \mathrm{mL}$ insulin, $60 \mu \mathrm{m}$ indomethacin (Sigma-Aldrich), and 10\% FBS. After 7 days, mRNA was isolated for adipogenic genes analysis. After 21 days, the cells were stained for cellular lipid droplets with Oil Red O (Sigma-Aldrich).

\section{Immunochemistry-paraffin (IHC-P) staining}

Immunochemistry was performed as previously reported [23]. In brief, the tissues were fixed in $4 \%$ formalin for 72 h at $4{ }^{\circ} \mathrm{C}$, decalcified in $10 \%$ EDTA for 3 weeks until easily pierced by a needle and then embedded in paraffin for the next procedure. Slides $(4 \mu \mathrm{m})$ were made and deparaffinized, and endogenous peroxidase was eliminated. After antigen blocking and retrieval, the slides were incubated with primary TGF- $\beta 1$ and fibronectin antibodies overnight at $4{ }^{\circ} \mathrm{C}$, thoroughly rinsed with PBS, incubated for $20 \mathrm{~min}$ and then stained with a DAB kit. The area of tissue with positive staining was quantified by ImageJ software (US National Institutes of Health).

\section{In vitro and in vivo siRNA interference assays}

Double-stranded siRNA was used to silence TGF- $\beta 1$ expression in ADSCs. The procedure and sequence used for the siRNA are available in the Additional file 1: Supplemental methods and Table S3. A satisfactory silencing efficiency in ADSCs was obtained after incubation on HA, and the cells were used in the animals with a medication history immediately post extraction (KD group).

\section{Tissue and cell RNA isolation and real-time polymerase} chain reaction (real-time PCR)

To lyse tissues into a paste, a mortar with liquid nitrogen and a high-throughput tissue crusher (Qiagen $\mathrm{GmbH}$, Hilden, Germany) were used for bone and gingival tissues. Both tissue and cell messenger RNA (mRNA) were isolated using TRIzol reagent (15,596, Invitrogen Corp., Carlsbad, CA). Messenger RNA was reverse transcribed into complementary DNA (cDNA) with the GoScript Reverse Transcription System (Promega, Madison, WI, USA), and an ABI Prism 7500 (Applied Bioscience, PerkinElmer, Foster City, CA) was used to perform quantitative PCR. The relative mRNA abundance of target genes was determined by normalizing to the GAPDH threshold cycle and calculated using the ${ }^{\Delta \Delta} \mathrm{Ct}$ method. The primers are listed in Additional file 1: Tables S1 and S2.

\section{Western blot assay}

Proteins were extracted from ADSCs and fibroblasts, and Western blot assays were performed as previously described [24]. Primary antibodies against GAPDH, transforming factor beta-1(TGF- $\beta 1$ ), were purchased from R\&D system (clone \#9016). 


\section{Bone parameter acquisition and analysis in different groups}

The bone parameters were analyzed as previously described [25]. Computed tomography (CT) data were harvested by three-dimensional multi-image cone beam CT (60 kV, 2 mA, J. Morita Corp., Kyoto, Japan) and imported into the Inveon Research Workplace (SIEMENS, Munich, Germany) for further analysis. The region of interest was depicted, and the bone mineral density (BMD) and BV/TV were calculated.

\section{Tartrate-resistant acid phosphatase (TRAP) staining}

TRAP staining was performed as previously described [26]. The specific process followed the instructions provided in the TRAP staining kit (Sigma-Aldrich, St. Louis, MO, USA), and the details are described in the Additional file 1: Supplemental methods.

\section{Statistical analysis}

All data are presented as the mean \pm STD from at least 3 independent animals. The differences between experimental groups were analyzed by using one-way analysis of variance (ANOVA) followed by Tukey's honestly significant difference (HSD) post hoc test by using GraphPad Prism 6 (GraphPad Software). A difference was considered significant if $p<0.05$ (indicated by an asterisk).

\section{Results}

Rabbit model of BRONJ-like lesions induced by BPs and DEX delivery

The induction of BRONJ-like animals followed the treatment schedule (Fig. 1a, b). At 8 weeks post extraction, the healthy group showed good healing (Fig. 2A) compared to the BP group, which exhibited retarded socket wound healing with partial jaw bone exposure. Histological analysis showed that extraction sockets from the healthy group presented a large proportion of cortical bone and cancellous bone (56.17 \pm $8.51 \%)$ formation. However, in the BP group, cancellous bone formation was barely observed, with much less to the regenerated cortical bone $(19.25 \pm 4.16 \%)$ (Fig. 2B, C). Furthermore, necrotic bone was found in the $\mathrm{BP}$ group and was surrounded by bacterial infection, with pus formation. To investigate the collagen deposition in each group, Masson staining, which was quantified by using ImageJ, indicated that a greater proportion of collagen deposition beneath the gingival wound of the extraction socket was found in the healthy group $(54.13 \pm 2.53 \%)$ than in the BRONJ-like group $(44.0 \pm 2.61 \%)$ (Fig. $2 \mathrm{~B}, \mathrm{C})$.
Local transplantation of ADSCs promotes gingival wound healing and prevents the occurrence of BRONJ-like lesions The cells, which we defined as adipose stem cells (ADSCs), were positive for CD44, CD90, CD105 and CD73 and were capable of osteogenesis and adipogenesis. (Additional file 1: Figure S1). Local transplantation of ADSCs was based on the described procedure (Fig. 1C, D). At 8 weeks after post extraction, both the ADSC and the healthy groups showed complete soft tissue coverage of the extraction socket, and no necrotic bone exposure was observed compared with the $\mathrm{BP}$ and the HA groups (Fig. 3A). Notably, local transplantation of ADSCs induced primary gingival wound healing at 2 weeks post extraction, which indicated that the unhealed extraction wound area $\left(\mathrm{mm}^{2}\right)$ was smaller after local transplantation of ADSCs $\left(0.77 \pm 0.48 \mathrm{~mm}^{2}\right)$, and this outcome was more consistent with the healthy group $\left(0.647 \pm 0.144 \mathrm{~mm}^{2}\right)$ than the BP $\left(7.152 \pm 5.874 \mathrm{~mm}^{2}\right)$ and HA $\left(3.86 \pm 3.03 \mathrm{~mm}^{2}\right.$ ) groups (Fig. 3A, C). Interestingly, with the early gingival covering at 2 weeks post extraction, less inflammatory infiltration was found under the socket connective tissues after local transplantation of ADSCs (Fig. 3B). The proportion of collagen deposition in the subgingival connective tissue of the tooth extraction socket was significantly higher in the ADSC and healthy groups than in the BP and HA groups 2 weeks after extraction $(49.36 \pm 11 \%$ and $60.18 \pm 5.35 \%$ vs. $16.90 \pm 7.37 \%$ and $23.35 \pm 4.96 \%$ ), suggesting that ADSCs promote subgingival connective tissue collagen deposition and accelerate the healing of gingival wounds (Fig. 3C). Local ADSC transplantation also rescued the number of osteoclasts per linear bone perimeter $(\# / \mathrm{mm})$ compared to the BP group (Fig. 3D), indicating a revived bone remodeling process. Thus, local ADSC transplantation can promote gingival wound healing and collagen deposition.

\section{Primary gingival healing by transplantation of ADSCs facilitate socket bone regeneration and upregulate osteogenic genes expression}

Following the primary gingival wound healing observed at 2 weeks post extraction, a large proportion of new bone regeneration $(40.23 \pm 16.62 \%)$ was also found in the ADSC group at 8 weeks post extraction (Fig. 4A). Histological analysis ( $\mathrm{H} \& \mathrm{E}$ and Masson staining) indicated a lower proportion of necrotic bone in the ADSC group (3.30 \pm $3.18 \%$ ), which showed a pattern similar to that in the healthy group $(2.075 \pm 1.81 \%)$, rather than that in the BP $(30.60 \pm 11.24 \%)$ and HA groups $(14.21 \pm 6.94 \%)$ (Fig. $4 \mathrm{~A})$. Cone beam computed tomography (CBCT) examination revealed that the extraction sockets in the ADSC and healthy groups were mostly occupied by regenerative bone, but no obvious new bone regeneration was observed in the $\mathrm{BP}$ and HA groups (Fig. 4B), which is consistent with the osteogenic genes relative expression in bone tissue being significantly upregulated in the ADSC and healthy groups 
A

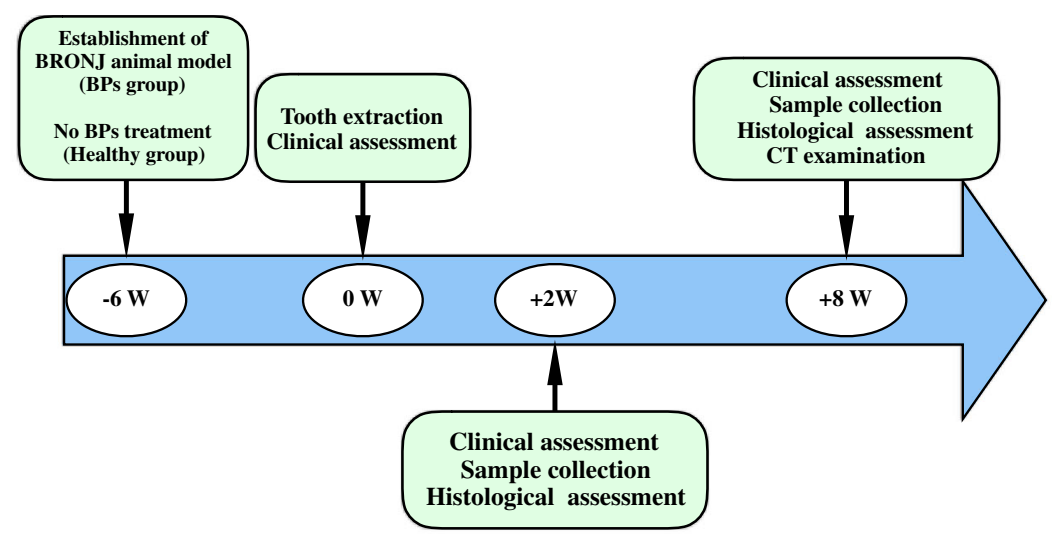

B
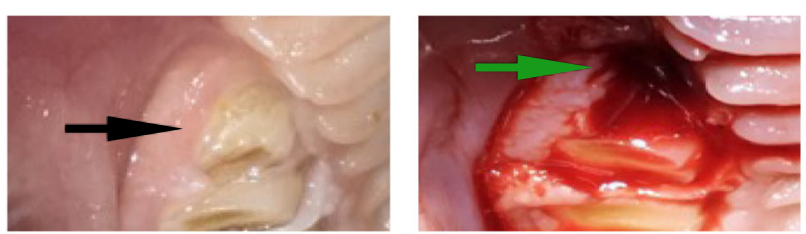

C
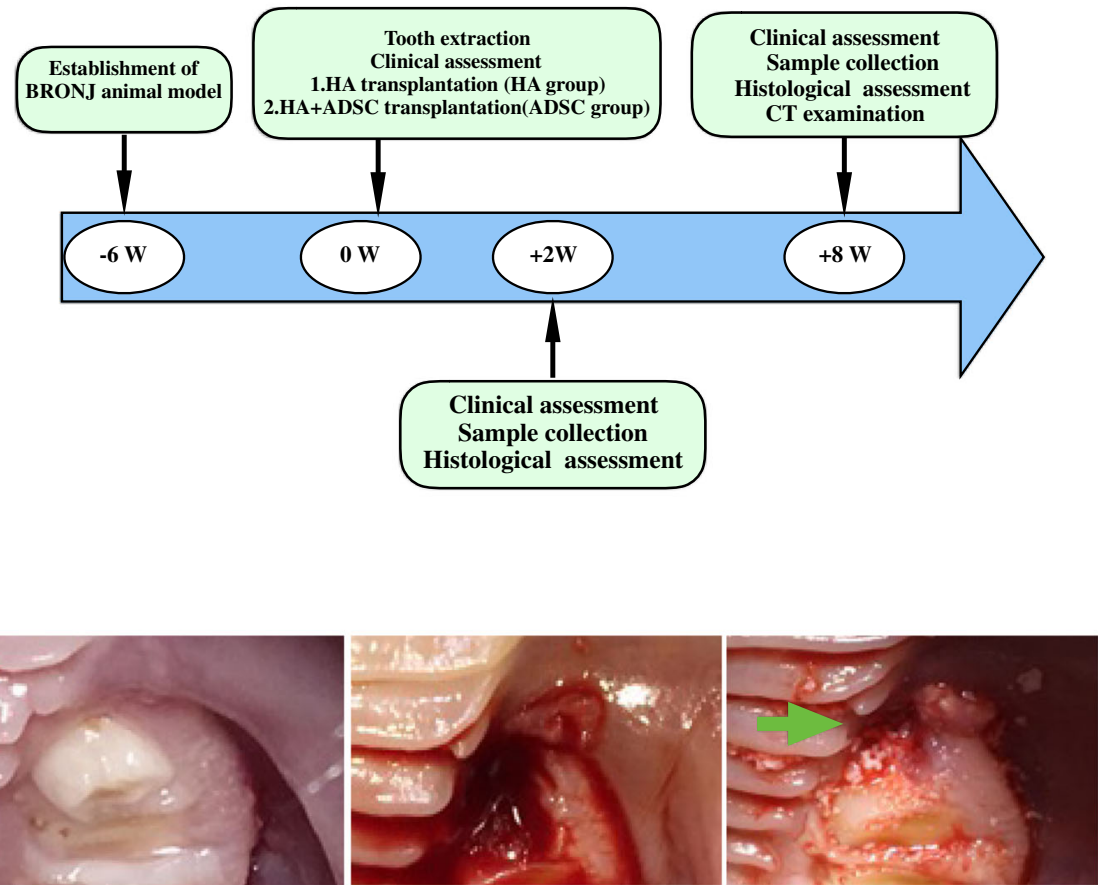

Fig. 1 The treatment schedule used to induce BRONJ-like animals and the ADSC transplantation procedure. a Animals were divided into two groups, the healthy group (non-medication treated) and the BP group. The BP group was treated with zoledronic acid (ZOL) and dexamethasone (DEX). After the sixth dose of ZOL+DEX treatment, the bilateral premolars were extracted in both the healthy and BP groups. At 2 weeks and 8 weeks post extraction, samples were collected. $\mathbf{b}$ The procedure for tooth extraction and an extracted tooth (bar $=2 \mathrm{~mm}$ ). $\mathbf{c}$ Animals were divided into two groups: the hydroxyapatite (HA) group and the ADSC group. Both groups were treated with ZOL+DEX once per week and followed the same schedule used to induce BRONJ-like animals. $\mathbf{d}$ The two groups were subjected to extraction of the bilateral premolars. Simultaneously, after tooth extraction, the HA group was filled with hydroxyapatite, and the ADSC group was filled with ADSCs that were incubated on HA. Arrows indicate filled HA or ADSC-HA complex 


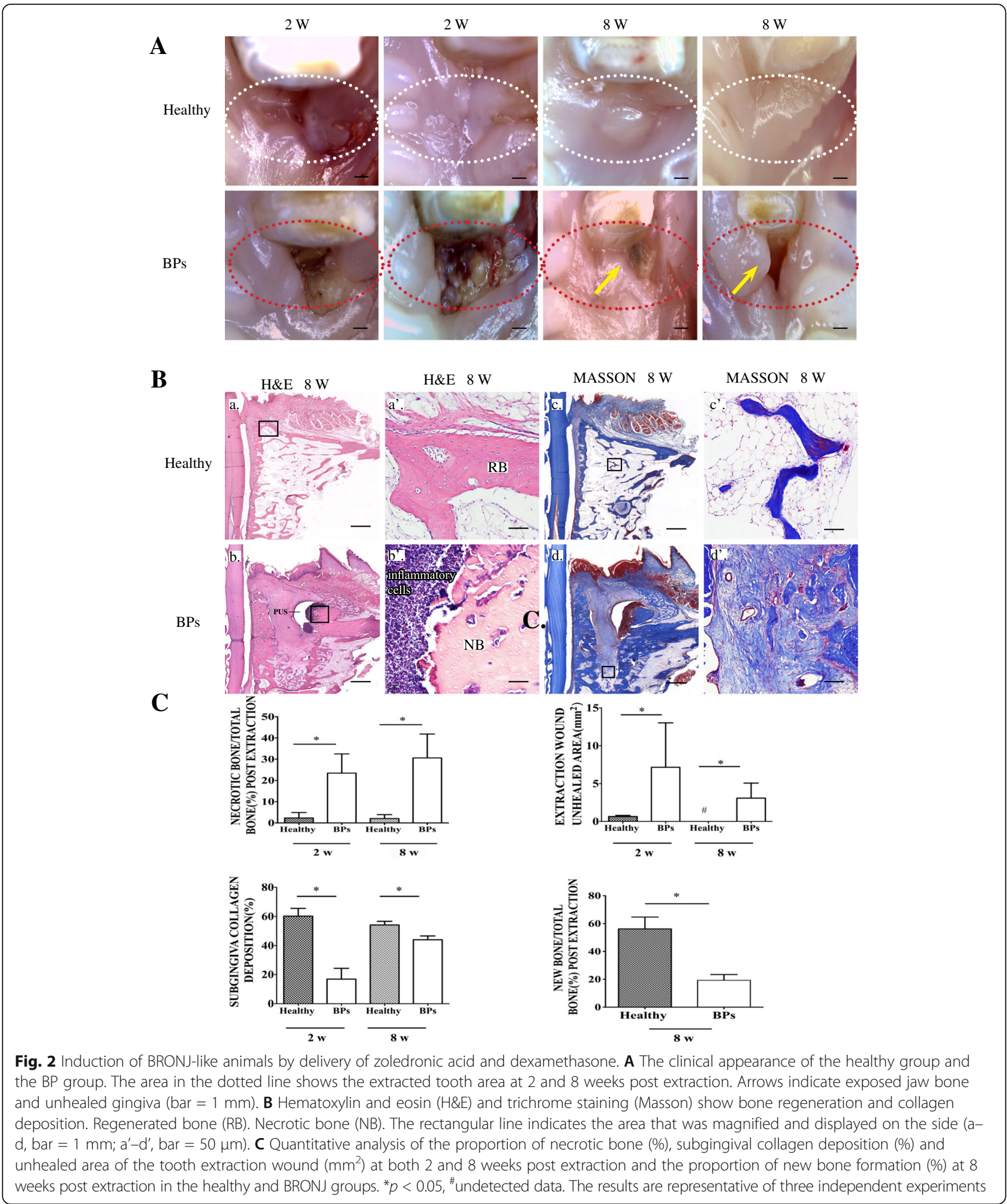

than in the BP group (Fig. 4C). Bone volume/total volume (BV/TV) and BMD in the ADSC group were significantly increased compared with those in the BP and HA groups and similar to those in the healthy group (Fig. 4B).
Local ADSC transplantation improved suppressed TGF- $\beta 1$ and fibronectin expression in BRONJ-like rabbits

According to previous results, the gingival epithelium was mostly healed in the ADSC and healthy groups but not in 

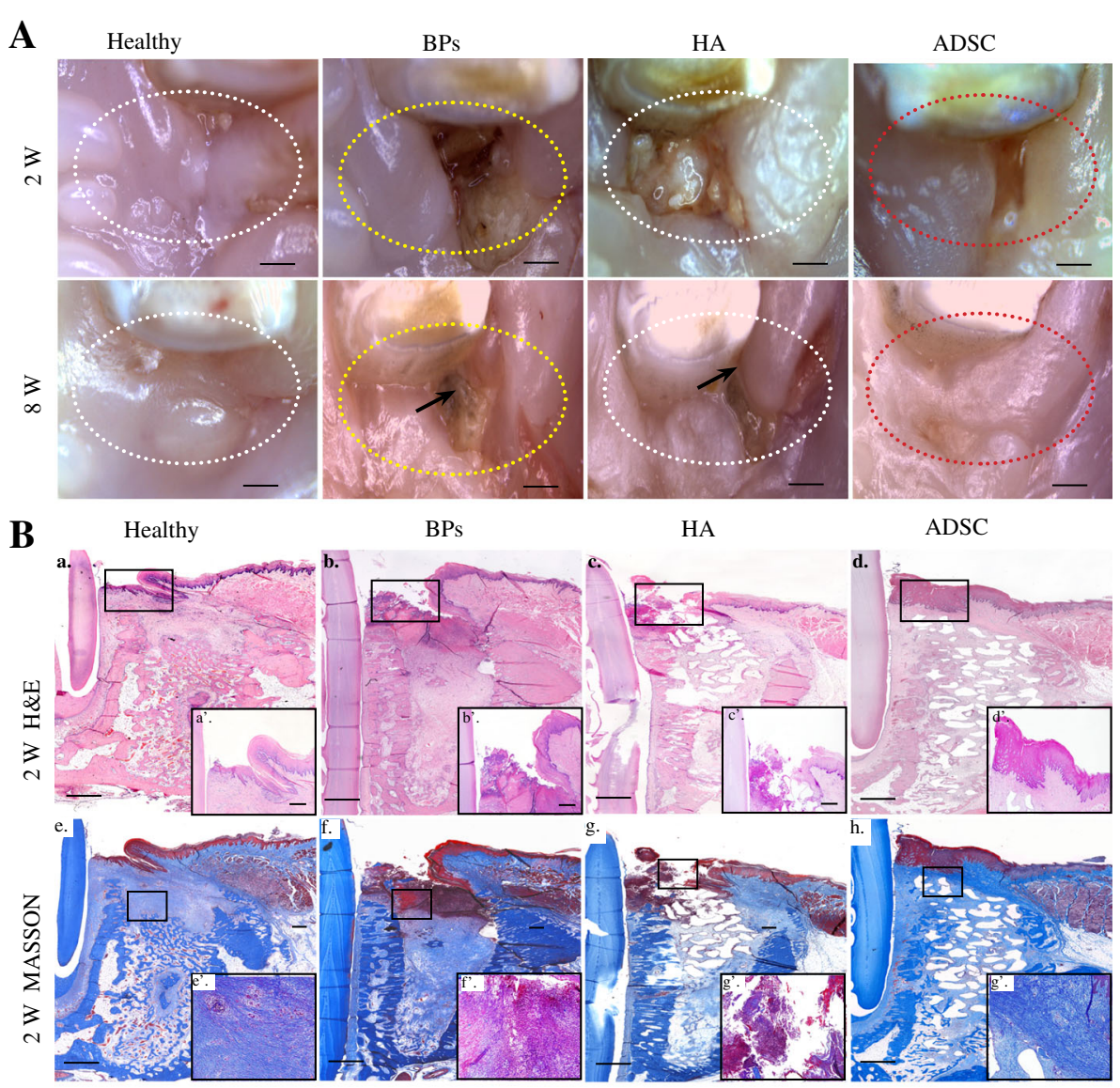

BPs

HA

ADSC
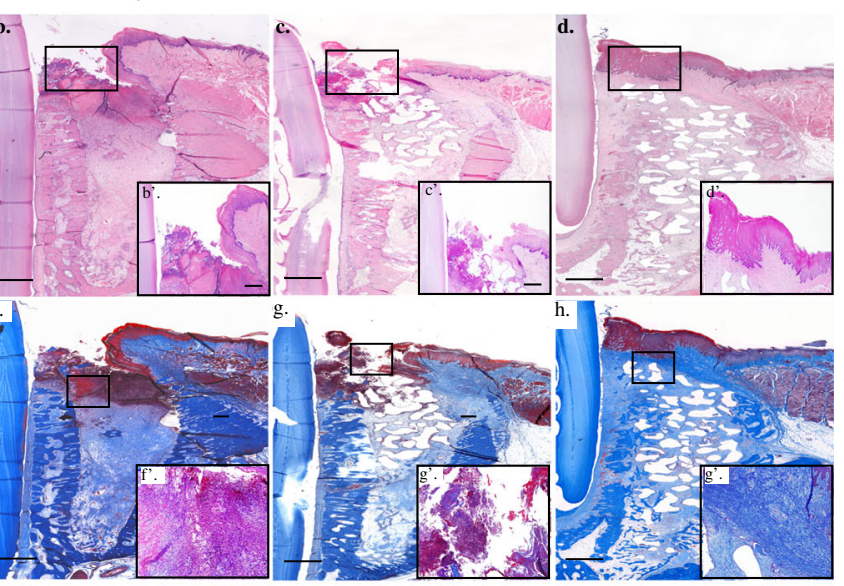

C
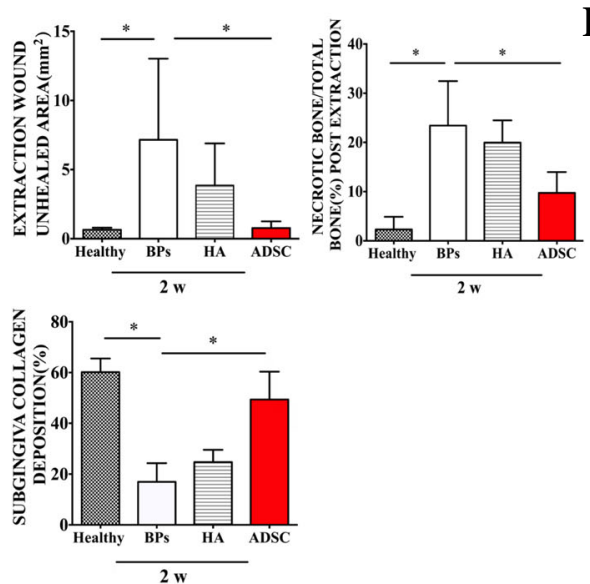

D

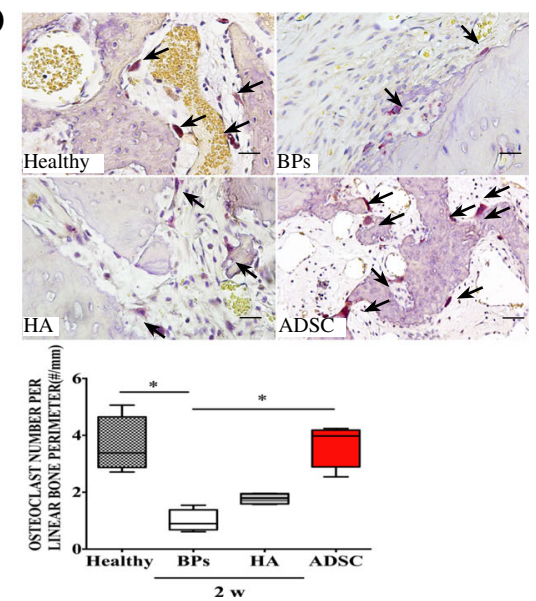

Fig. 3 Local ADSC therapy promotes primary gingival healing at 2 weeks post extraction and facilitates bone regeneration at 8 weeks post extraction. A Clinical appearance of the healthy, BP, HA, and ADSC groups at 2 and 8 weeks post extraction. Areas in the dotted line show the tooth extraction site. Black arrows indicate jaw bone exposure in the BP group (bar $=1 \mathrm{~mm}$ ). $\mathbf{B}$ H\&E staining shows gingival healing in each group at 2 weeks post extraction. Masson staining indicates extraction site subgingival collagen deposition (a-h, bar $=1 \mathrm{~mm} ; \mathrm{a}^{\prime}-\mathrm{d}^{\prime}$, bar $=200$ $\left.\mu \mathrm{m} ; \mathrm{e}^{\prime}-\mathrm{h}^{\prime}, \mathrm{bar}=50 \mu \mathrm{m}\right)$. The rectangular line shows the magnified area. C Quantification of the unhealed area of the tooth extraction wound $\left(\mathrm{mm}^{2}\right)$, the proportions of necrotic (\%), and collagen deposition (\%) in each group at 2 weeks. ${ }^{*} p<0.05$. D TRAP-positive cells indicate osteoclasts. The arrows indicate osteoclasts, bar $=50 \mu \mathrm{m}$. Quantification of the number of osteoclasts per linear bone perimeter (\#/mm), ${ }^{*} p<0.05$

the $\mathrm{BP}$ and HA groups at 2 weeks post extraction, which indicated that ADSCs promote gingival wound healing within 2 weeks post extraction (Fig. 3A). DiR was used as a fluorescent stain to label live ADSCs, which verified that
ADSCs survived for 2 weeks after tooth extraction (Additional file 1: Figure S2). To further investigate the mechanism by which ADSCs promote primary gingival wound healing, total gingiva and bone tissue were harvested, and 


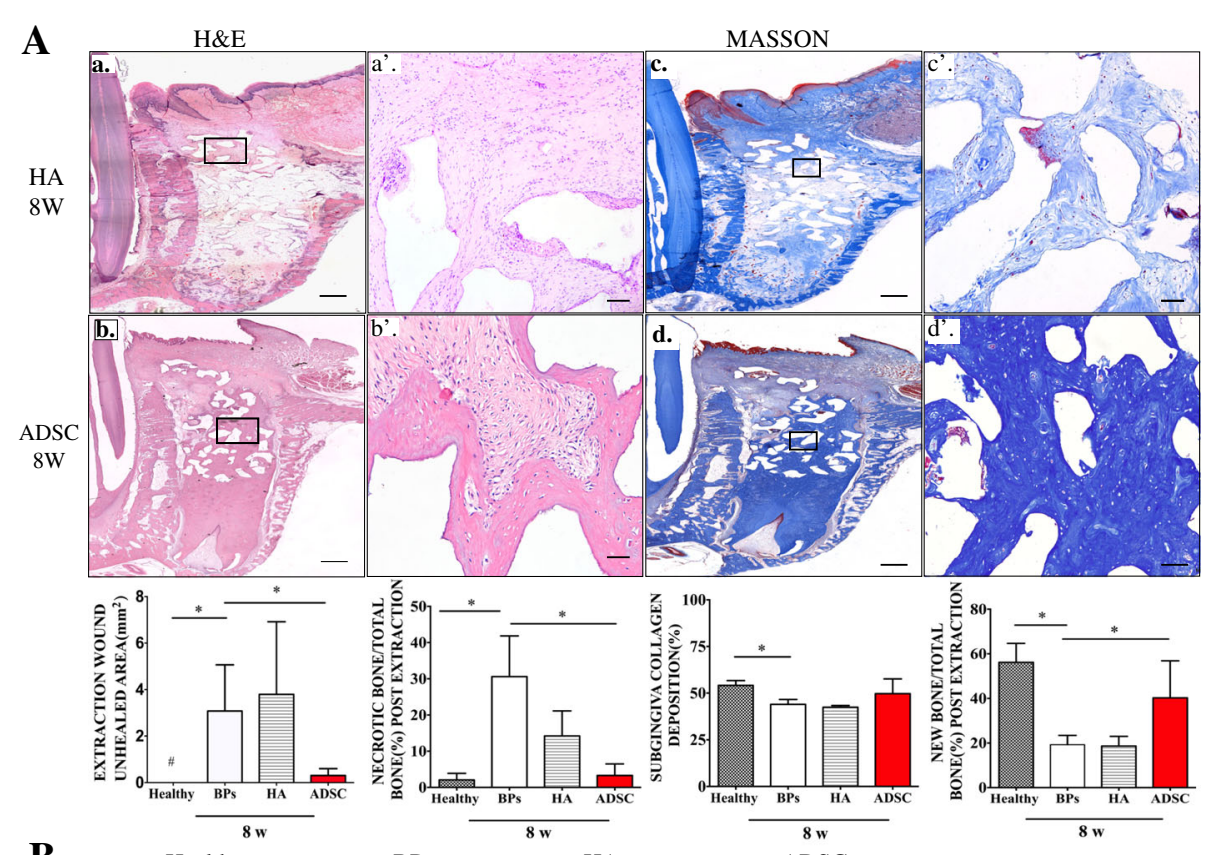

B

BPs

ADSC
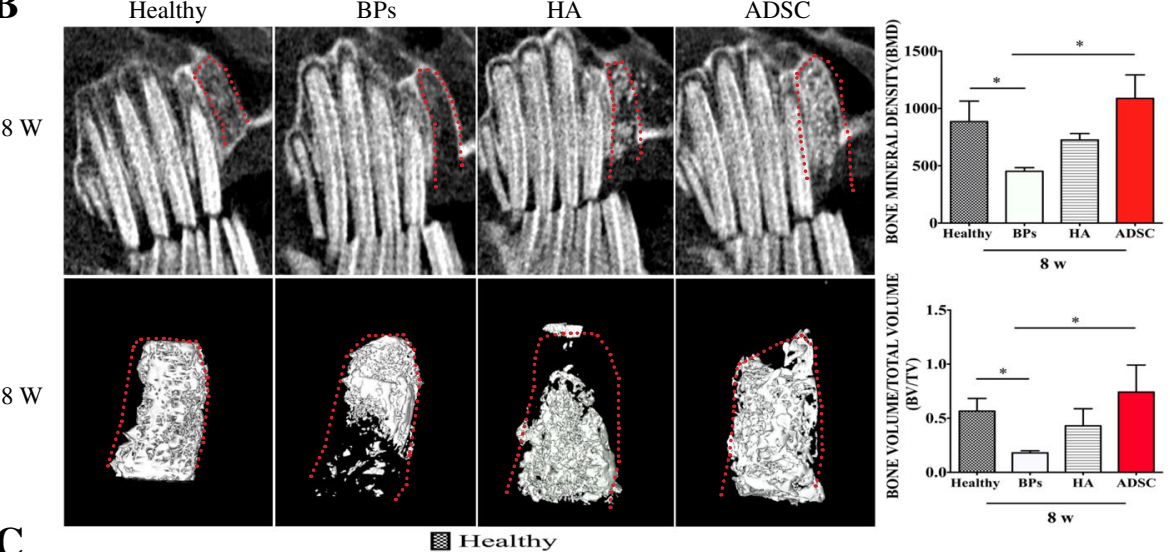

$\mathbf{C}$

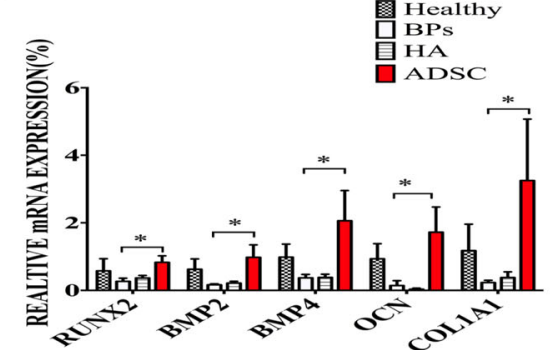

Fig. 4 Primary gingival healing by transplantation of ADSCs facilitate socket bone regeneration and upregulate osteogenic genes expression. $\mathbf{A}$ Local ADSC therapy facilitates socket bone regeneration. H\&E and Masson staining indicate bone regeneration in the ADSC and HA groups (a-d, bar $=1 \mathrm{~mm} ; \mathrm{a}^{\prime}-\mathrm{d}^{\prime}$, bar $\left.=50 \mu \mathrm{m}\right)$. Quantification of the unhealed area of the tooth extraction wound $\left(\mathrm{mm}^{2}\right)$, the proportion of necrotic bone $(\%)$, new bone formation (\%), and extraction socket subgingival collagen deposition (\%) in each group at 2 weeks post extraction. ${ }^{*} p<0.05$, \#undetected data. B Computed tomography (CT) examination shows reconstructed three-dimensional (3D) images and quantification of bone volume/total volume (BV/TV) and bone mineral density (BMD) in each group. ${ }^{*} p<0.05$. The results are representative of three independent experiments. C Relative expression of osteogenic target genes in each group. ${ }^{*} p<0.05$

mRNA levels were determined by quantitative PCR. TGF$\beta 1$ and fibronectin were the most significantly downregulated in the BP and HA groups compared with the healthy group; however, both of these factors were highly expressed in the ADSC group (Fig. 5A). The same pattern was further confirmed by immunohistochemistry, which showed a higher expression of TGF- $\beta 1$ and fibronectin in the ADSC group than that in the $\mathrm{BP}$ and $\mathrm{HA}$ groups (Fig. 5B, C). 


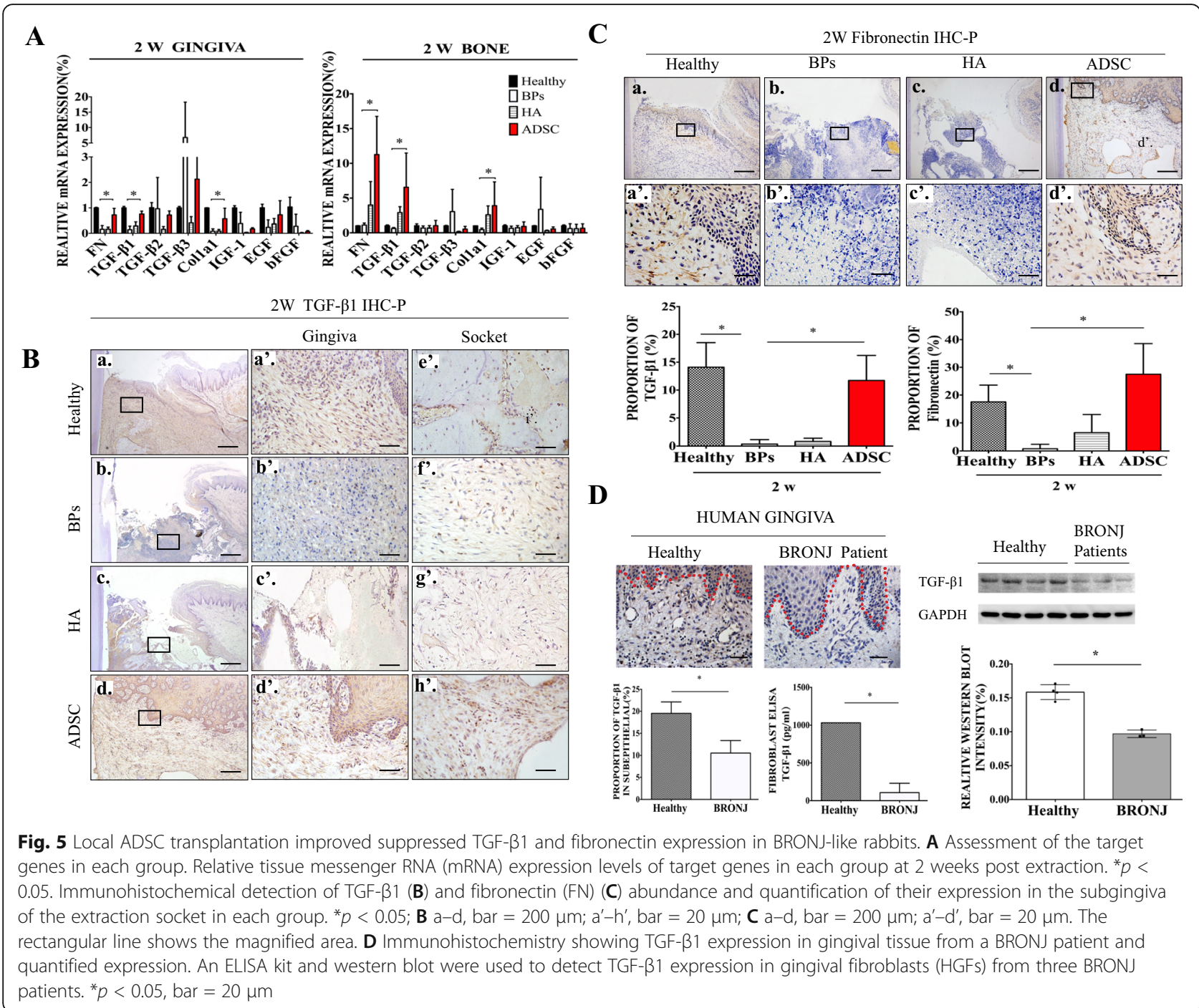

Furthermore, patients' gingival samples from BRONJ lesions confirmed impaired TGF- $\beta 1$ expression in BP gingival tissue. The TGF- $\beta 1$ levels of patients' gingival fibroblasts were further verified a decreased pattern by ELISA assay and western blot (Fig. 5D). Thus, ADSCs may prevent the onset of BRONJ by inducing TGF- $\beta 1$ and fibronectin expression.

\section{TGF- $\beta 1$ deficiency eliminated the ability of ADSCs to} accelerate gingival wound healing in BP-treated animals TGF- $\beta 1$ played a pivotal role in ADSC-mediated acceleration of wound healing [27-29]. Moreover, the expression of TGF- $\beta 1$ follows positive feedback regulation [30]. To test the role of TGF- $\beta 1$ in ADSC-mediated accelerated gingival wound healing in BP-treated animals, siRNA was applied to knock down TGF- $\beta 1$ expression in ADSCs during BRONJ-like prevention, as described above. The silencing efficiency of TGF- $\beta 1$ was confirmed by real-time PCR, ELISA, and western blotting (Additional file 1: Figure
S3). The unhealed extraction wound area in the KD group $\left(2.20 \pm 0.35 \mathrm{~mm}^{2}\right)$ was larger than that in the ADSC group $\left(0.77 \pm 0.48 \mathrm{~mm}^{2}\right)$ (Fig. 6A). Real-time PCR indicated that both TGF- $\beta 1$ and fibronectin were suppressed in the KD group (Fig. 6B). Histological analysis revealed histological features similar to those of the BP group, which exhibited partial inflammatory infiltration beneath the gingival tissue and less collagen deposition $(25.42 \pm 8.22 \%)$ in connective tissue than the ADSC group (49.36 $\pm 11 \%$ ) (Fig. 6C). Immunohistochemistry showed that TGF- $\beta 1$ expression in the subgingiva was significantly diminished in the $\mathrm{KD}$ group compared to that in the ADSC group (Fig. 6D), which verified that TGF- $\beta 1$ played a pivotal role in ADSCaccelerated gingival healing.

\section{Discussion}

The highest incidence of BRONJ is observed in malignant tumor patients treated with a combination of BPs and DEX. However, based on the current treatment 


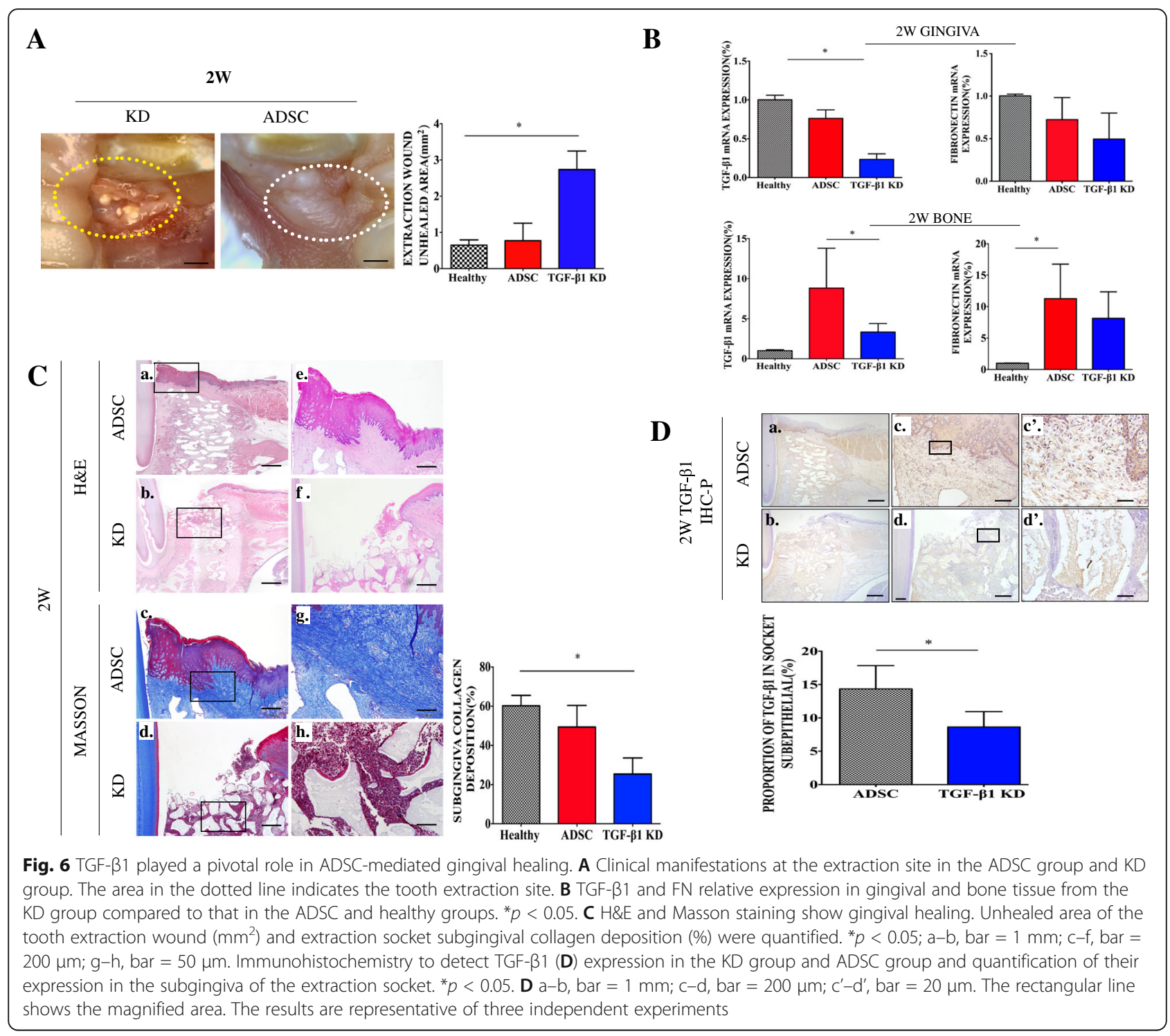

method, the cure rate of BRONJ is only $58.5 \%$ [31]. It is particularly important to prevent the occurrence of $\mathrm{BRONJ}$ in patients with a medication history following a tooth extraction or other dentoalveolar surgery. In our study, we successfully induced a BRONJ-like rabbit model by simulating the clinical application of BPs and immunosuppressive drugs. BRONJ was successfully prevented when ADSCs were transplanted into the extraction wound. We first showed that ADSC transplantation elevated TGF- $\beta 1$ and fibronectin expression under BRONJ conditions, contributing to the promotion of gingival wound healing and facilitating bone regeneration. Furthermore, when we knocked down TGF- $\beta 1$ in ADSCs, these cells failed to promote primary gingival wound healing. In summary, local ADSC transplantation proved that ADSCs can mediate gingival wound healing through TGF- $\beta 1$, and early soft tissue healing accelerated by ADSCs is important for preventing the onset of BRONJ.

In our study, we found that TGF- $\beta 1$ and fibronectin expression was suppressed not only in BP-treated animal but also in patient gingival lesions, which may be connected to delayed gingival healing in BRONJ. During normal wound healing, fibronectin can induce the regeneration of epithelial tissue by recognizing the RGD sequence on the epithelial cell integrin receptor $\alpha 5 \beta 1$ $[32,33]$. However, the absence of fibronectin expression in irradiated skin leads to skin wounds that do not heal properly [34]. It was also reported that fibronectin is regulated by TGF- $\beta 1$ in a $c$-Jun $\mathrm{N}$-terminal kinasedependent and Smad4-independent manner [35]. Other studies also showed that BPs could inhibit the TGF- $\beta 1$ pathway [36], leading to collagen deposition and restricted downstream signaling. The retarded gingival 
for important intellectual content. All authors read and approved the final manuscript.

\section{Funding}

This work was supported by a grant from the National Natural Science Foundation of China (No. 81371117) and the Beijing Natural Science Foundation (No. 7152155 \& No. 7192230). The funding agencies had no role in the project design, experimental execution, analysis of the results, or preparation of the manuscript.

\section{Availability of data and materials}

All data generated or analyzed during this study are included in this published article. All methods and materials used in this study are listed in Additional file 1 .

\section{Ethics approval and consent to participate}

The experimental procedures in this experiment to animals were under an institutionally approved protocols of animal research at Peking University (LA2018017)

\section{Consent for publication}

Not applicable.

\section{Competing interests}

The authors declare that they have no competing interests.

\section{Author details}

${ }^{1}$ Department of Oral and Maxillofacial Surgery, Peking University School and Hospital of Stomatology, 22 Zhongguancun Nandajie, Haidian District, Beijing 100081, People's Republic of China. ${ }^{2}$ National Engineering Laboratory for Digital and Material Technology of Stomatology, Beijing Key Laboratory of Digital Stomatology, Beijing, China.

Received: 6 January 2019 Revised: 27 March 2019 Accepted: 23 May 2019 Published online: 13 June 2019

\section{References}

1. Ruggiero SL, Dodson TB, Fantasia J, Goodday R, Aghaloo T, Mehrotra B, O'Ryan F, O American Association of and S Maxillofacial. American Association of Oral and Maxillofacial Surgeons position paper on medication-related osteonecrosis of the jaw--2014 update. J Oral Maxillofac Surg. 2014;72:1938-56.

2. Berenson JR, Rosen LS, Howell A, Porter L, Coleman RE, Morley W, Dreicer R, Kuross SA, Lipton A, Seaman JJ. Zoledronic acid reduces skeletal-related events in patients with osteolytic metastases. Cancer. 2001:91:1191-200.

3. Ruggiero SL, Drew SJ. Osteonecrosis of the jaws and bisphosphonate therapy. J Dent Res. 2007:86:1013-21.

4. Ogata K, Katagiri W, Osugi M, Kawai T, Sugimura Y, Hibi H, Nakamura S, Ueda M. Evaluation of the therapeutic effects of conditioned media from mesenchymal stem cells in a rat bisphosphonate-related osteonecrosis of the jaw-like model. Bone. 2015;74:95-105.

5. Kikuiri T, Kim I, Yamaza T, Akiyama K, Zhang Q, Li Y, Chen C, Chen W, Wang S, Le AD, Shi S. Cell-based immunotherapy with mesenchymal stem cells cures bisphosphonate-related osteonecrosis of the jaw-like disease in mice. J Bone Miner Res. 2010;25:1668-79.

6. Vahtsevanos K, Kyrgidis A, Verrou E, Katodritou E, Triaridis S, Andreadis CG, Boukovinas I, Koloutsos GE, Teleioudis Z, Kitikidou K, Paraskevopoulos P, Zervas K, Antoniades K. Longitudinal cohort study of risk factors in cancer patients of bisphosphonate-related osteonecrosis of the jaw. J Clin Oncol. 2009;27:5356-62.

7. Fliefel R, Troltzsch M, Kuhnisch J, Ehrenfeld M, Otto S. Treatment strategies and outcomes of bisphosphonate-related osteonecrosis of the jaw (BRONJ) with characterization of patients: a systematic review. Int J Oral Maxillofac Surg. 2015:44:568-85.

8. Matsumoto A, Sasaki M, Schmelzeisen R, Oyama Y, Mori Y, Voss PJ. Primary wound closure after tooth extraction for prevention of medication-related osteonecrosis of the jaw in patients under denosumab. Clin Oral Investig. 2017;21:127-34

9. Ristow O, Ruckschloss T, Bodem J, Berger M, Bodem E, Kargus S, Engel M, Hoffmann J, Freudlsperger C. Double-layer closure techniques after bone surgery of medication-related osteonecrosis of the jaw - a single center cohort study. J Craniomaxillofac Surg. 2018;46:815-24.

10. Nonnenmuhlen N, Burnic A, Bartella A, Lethaus B, Gerhards F, Ristow O, Pautke C, Holzle F, Steiner T. Comparison of mucosal and mucoperiosteal wound cover for the treatment of medication-related osteonecrosis of the jaw lesions: a retrospective cohort study. Clin Oral Investig. 2019;23:351-9.

11. Hasegawa T, Kawakita A, Ueda N, Funahara R, Tachibana A, Kobayashi M, Kondou E, Takeda D, Kojima Y, Sato S, Yanamoto S, Komatsubara H, Umeda M, Kirita T, Kurita H, Shibuya Y, Komori T, M Japanese Study Group of Cooperative Dentistry with. A multicenter retrospective study of the risk factors associated with medication-related osteonecrosis of the jaw after tooth extraction in patients receiving oral bisphosphonate therapy: can primary wound closure and a drug holiday really prevent MRONJ? Osteoporos Int. 2017;28:2465-73.

12. Hassan WU, Greiser U, Wang W. Role of adipose-derived stem cells in wound healing. Wound Repair Regen. 2014;22:313-25.

13. Kato Y, Iwata T, Morikawa S, Yamato M, Okano T, Uchigata Y. Allogeneic transplantation of an adipose-derived stem cell sheet combined with artificial skin accelerates wound healing in a rat wound model of type 2 diabetes and obesity. Diabetes. 2015;64:2723-34.

14. Li CY, Wu XY, Tong JB, Yang XX, Zhao JL, Zheng QF, Zhao GB, Ma ZJ. Comparative analysis of human mesenchymal stem cells from bone marrow and adipose tissue under xeno-free conditions for cell therapy. Stem Cell Res Ther. 2015;6:55

15. Strioga M, Viswanathan S, Darinskas A, Slaby O, Michalek J. Same or not the same? Comparison of adipose tissue-derived versus bone marrow-derived mesenchymal stem and stromal cells. Stem Cells Dev. 2012:21:2724-52

16. Kim WS, Park BS, Sung JH. The wound-healing and antioxidant effects of adipose-derived stem cells. Expert Opin Biol Ther. 2009;9:879-87.

17. Hu L, Wang J, Zhou X, Xiong Z, Zhao J, R Y, Huang F, Zhang H, Chen L. Exosomes derived from human adipose mensenchymal stem cells accelerates cutaneous wound healing via optimizing the characteristics of fibroblasts. Sci Rep. 2016:6:32993.

18. Li Y, Xu J, Mao L, Liu Y, Gao R, Zheng Z, Chen W, Le A, Shi S, Wang S. Allogeneic mesenchymal stem cell therapy for bisphosphonate-related jaw osteonecrosis in swine. Stem Cells Dev. 2013;22:2047-56.

19. Liao L, Shi B, Chang H, Su X, Zhang L, Bi C, Shuai Y, Du X, Deng Z, Jin Y. Heparin improves BMSC cell therapy: anticoagulant treatment by heparin improves the safety and therapeutic effect of bone marrow-derived mesenchymal stem cell cytotherapy. Theranostics. 2017;7:106-16.

20. Djouad F, Plence P, Bony C, Tropel P, Apparailly F, Sany J, Noel D, Jorgensen C. Immunosuppressive effect of mesenchymal stem cells favors tumor growth in allogeneic animals. Blood. 2003;102:3837-44.

21. Karnoub AE, Dash AB, Vo AP, Sullivan A, Brooks MW, Bell GW, Richardson AL, Polyak K, Tubo R, Weinberg RA. Mesenchymal stem cells within tumour stroma promote breast cancer metastasis. Nature. 2007:449:557-63.

22. Xiao E, Li JM, Yan YB, An JG, Duan DH, Gan YH, Zhang Y. Decreased osteogenesis in stromal cells from radiolucent zone of human TMJ ankylosis. J Dent Res. 2013;92:450-5.

23. Zhu X, Wang Y, Liu Y, Huang GT, Zhang C. Immunohistochemical and histochemical analysis of newly formed tissues in root canal space transplanted with dental pulp stem cells plus platelet-rich plasma. J Endod. 2014;40:1573-8

24. Yamada T, Yuasa M, Masaoka T, Taniyama T, Maehara H, Torigoe I, Yoshii T, Shinomiya K, Okawa A, Sotome S. After repeated division, bone marrow stromal cells express inhibitory factors with osteogenic capabilities, and EphA5 is a primary candidate. Bone. 2013;57:343-54.

25. O'Neill KR, Stutz CM, Mignemi NA, Burns MC, Murry MR, Nyman JS, Schoenecker JG. Micro-computed tomography assessment of the progression of fracture healing in mice. Bone. 2012;50:1357-67.

26. Yang T, Zhang J, Cao Y, Zhang M, Jing L, Jiao K, Yu S, Wang M. Decreased bone marrow stromal cells activity involves in unilateral anterior crossbiteinduced early subchondral bone loss of temporomandibular joints. Arch Oral Biol. 2014;59:962-9.

27. Jung $H$, Kim HH, Lee DH, Hwang YS, Yang HC, Park JC. Transforming growth factor-beta 1 in adipose derived stem cells conditioned medium is a dominant paracrine mediator determines hyaluronic acid and collagen expression profile. Cytotechnology. 2011;63:57-66.

28. Zhou BR, Xu Y, SL Guo YX, Wang Y, Zhu F, F Permatasari DW, Yin ZQ, Luo D. The effect of conditioned media of adipose-derived stem cells on wound 
healing after ablative fractional carbon dioxide laser resurfacing. Biomed Res Int. 2013;2013:519126.

29. Cho JW, Kang MC, Lee KS. TGF-beta1-treated ADSCs-CM promotes expression of type I collagen and MMP-1, migration of human skin fibroblasts, and wound healing in vitro and in vivo. Int J Mol Med. 2010;26: 901-6.

30. Li J, Tripathi BJ, Chalam KV, Tripathi RC. Transforming growth factor-beta 1 and -beta 2 positively regulate TGF-beta 1 mRNA expression in trabecular cells. Invest Ophthalmol Vis Sci. 1996;37:2778-82.

31. Wutzl A, Biedermann E, Wanschitz F, Seemann R, Klug C, Baumann A, Watzinger F, Schicho K, Ewers R, Millesi G. Treatment results of bisphosphonate-related osteonecrosis of the jaws. Head Neck. 2008;30:1224-30.

32. Tao T, Li Y, Gui C, Ma Y, Ge Y, Dai H, Zhang K, J D, Guo Y, Jiang Y, Gui J. Fibronectin enhances cartilage repair by activating progenitor cells through integrin alpha5beta1 receptor. Tissue Eng Part A. 2018; 24:1112-24.

33. To WS, Midwood KS. Plasma and cellular fibronectin: distinct and independent functions during tissue repair. Fibrogenesis Tissue Repair. 2011;4:21.

34. Johnson MB, Pang B, Gardner DJ, Niknam-Benia S, Soundarajan V, Bramos A, Perrault DP, Banks K, Lee GK, Baker RY, Kim GH, Lee S, Chai Y, Chen M, Li W, Kwong L, Hong YK, Wong AK. Topical fibronectin improves wound healing of irradiated skin. Sci Rep. 2017;7:3876.

35. Hocevar BA, Brown TL, Howe PH. TGF-beta induces fibronectin synthesis through a c-Jun N-terminal kinase-dependent, Smad4-independent pathway. EMBO J. 1999;18:1345-56.

36. Kim S, Williams DW, Lee C, Kim T, Arai A, Shi S, Li X, Shin KH, Kang MK, Park $\mathrm{NH}$, Kim RH. IL-36 induces bisphosphonate-related osteonecrosis of the jawlike lesions in mice by inhibiting TGF-beta-mediated collagen expression. J Bone Miner Res. 2017;32:309-18.

37. Mawardi H, Giro G, Kajiya M, Ohta K, Almazrooa S, Alshwaimi E, Woo SB, Nishimura I, Kawai T. A role of oral bacteria in bisphosphonate-induced osteonecrosis of the jaw. J Dent Res. 2011;90:1339-45.

38. Ziebart T, Halling F, Heymann P, Neff A, Blatt S, Jung J, Pabst A, Righesso L, Walter C. Impact of soft tissue pathophysiology in the development and maintenance of bisphosphonate-related osteonecrosis of the jaw (BRONJ). Dentistry Journal. 2016;4:36.

39. Lima LL, Goncalves PF, Sallum EA, Casati MZ, Nociti FH Jr. Guided tissue regeneration may modulate gene expression in periodontal intrabony defects: a human study. J Periodontal Res. 2008;43:459-64.

40. Turri A, Elgali I, Vazirisani F, Johansson A, Emanuelsson L, Dahlin C, Thomsen P, Omar O. Guided bone regeneration is promoted by the molecular events in the membrane compartment. Biomaterials. 2016;84:167-83.

41. Chan JK, Harry L, Williams G, Nanchahal J. Soft-tissue reconstruction of open fractures of the lower limb: muscle versus fasciocutaneous flaps. Plast Reconstr Surg. 2012;130:284e-95e.

42. Liu R, Schindeler A, Little DG. The potential role of muscle in bone repair. J Musculoskelet Neuronal Interact. 2010;10:71-6.

43. Elgali I, Omar O, Dahlin C, Thomsen P. Guided bone regeneration: materials and biological mechanisms revisited. Eur J Oral Sci. 2017;125:315-37.

44. Taguchi Y, Amizuka N, Nakadate M, Ohnishi H, Fujii N, Oda K, Nomura S, Maeda T. A histological evaluation for guided bone regeneration induced by a collagenous membrane. Biomaterials. 2005;26:6158-66.

45. Tamama K, Kerpedjieva SS. Acceleration of wound healing by multiple growth factors and cytokines secreted from multipotential stromal cells/ mesenchymal stem cells. Adv Wound Care (New Rochelle). 2012;1:177-82.

46. Lee DE, Ayoub N, Agrawal DK. Mesenchymal stem cells and cutaneous wound healing: novel methods to increase cell delivery and therapeutic efficacy. Stem Cell Res Ther. 2016;7:37.

47. Kim WS, Park BS, Sung JH, Yang JM, Park SB, Kwak SJ, Park JS. Wound healing effect of adipose-derived stem cells: a critical role of secretory factors on human dermal fibroblasts. J Dermatol Sci. 2007:48:15-24.

48. Lichtman MK, Otero-Vinas M, Falanga V. Transforming growth factor beta (TGF-beta) isoforms in wound healing and fibrosis. Wound Repair Regen. 2016;24:215-22.

49. Jun EK, Zhang Q, Yoon BS, Moon JH, Lee G, Park G, Kang PJ, Lee JH, Kim A, You S. Hypoxic conditioned medium from human amniotic fluid-derived mesenchymal stem cells accelerates skin wound healing through TGF-beta/ SMAD2 and PI3K/Akt pathways. Int J Mol Sci. 2014;15:605-28.

50. Nie C, Zhang G, Yang D, Liu T, Liu D, Xu J, Zhang J. Targeted delivery of adipose-derived stem cells via acellular dermal matrix enhances wound repair in diabetic rats. J Tissue Eng Regen Med. 2015;9:224-35.
51. Yamano S, Kuo WP, Sukotjo C. Downregulated gene expression of TGF-betas in diabetic oral wound healing. J Craniomaxillofac Surg. 2013;41:e42-8.

\section{Publisher's Note}

Springer Nature remains neutral with regard to jurisdictional claims in published maps and institutional affiliations.
Ready to submit your research? Choose BMC and benefit from:

- fast, convenient online submission

- thorough peer review by experienced researchers in your field

- rapid publication on acceptance

- support for research data, including large and complex data types

- gold Open Access which fosters wider collaboration and increased citations

- maximum visibility for your research: over $100 \mathrm{M}$ website views per year

At BMC, research is always in progress.

Learn more biomedcentral.com/submissions 